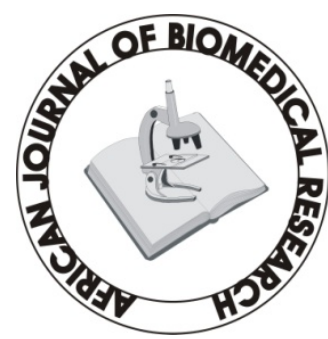

Full-text available at http://www.ajbrui.com http://www.bioline.br/md http://www.ajol.com

Received:

September 2006

Accepted (Revised): August 2007

Published

May 2008
Short communication

\section{Prevalence of Infertility in Women in a Southwestern Nigerian Community}

\author{
${ }^{1}$ Sule J.O., P. Erigbali ${ }^{2}$, L. Eruom ${ }^{2}$ \\ ${ }^{1}$ Department of Medical Biochemistry \\ Niger Delta University, Bayelsa State, Nigeria \\ ${ }^{2}$ Department of Physiology, Niger Delta University. \\ Niger Delta University, Bayelsa State, Nigeria
}

\section{ABSTRACT}

The prevalence and common causes of infertility in women aged between 15 and 55 years was assessed in four hospital centers in Osun State, located in the SouthWestern part of Nigeria. A survey of a consecutive sample of 200 cases of infertility were carried out in four hospital centers with a total of 50 cases of infertility evaluated in each of the centers between 2001 - 2003. The incidence of high infertility in women was established in all the centers; (Obafemi Awolowo University Teaching Hospital, Ile-Ife), 59.4\%, (Obafemi Awolowo University Teaching Hospital, Ilesa), 47.7\%, (Ladoke Akintola University Teaching Hospital, Oshogbo), 54.8\% and (General Hospital, Ikire), $44.2 \%$. $77.5 \%$ was recorded for a high rate of secondary Infertility, while Primary Infertility was $22.5 \%$. The commonest causes of infertility in this environment were, the tubal factor, uterine factor, and ovarian factor representing $39.5 \%, 30 \%$ and $13 \%$ respectively. The least common cause were cervical factor, Pelvic Infection Disease (PID), and endometriosis which was seen in $3 \%, 5.5 \%$ and $2.5 \%$ of the subjects respectively. There was also prevalence of infertility between the ages: $15-25$ years at the rate of $17 \%$, while $26-35$ years at the rate of $31.5 \%$. The majority of the cases occurred between the ages of $36-45$ at the rate of $50.5 \%$ and between $46-55$ years at the rate $1 \%$.

(Afr. J. Biomed. Res. 11: 225 - 227)

Key words: Infertility, Pelvic Infection Disease (PID), endometriosis.

*Address for Correspondence: j_sule@yahoo.com 


\section{INTRODUCTION}

In Africa, children are the fabric of any society, without which no meaningful social and economic progress is considered worthwhile. Infertility is defined as the inability of couples to achieve conception despite frequent, unprotected sexual intercourse for one year duration (Belsey, 1976). Infertility also includes the inability to carry a pregnancy to the delivery of a live baby. WHO in 1991 estimated that between 8 and 12\% of couples experienced some form of infertility during their reproductive lives, thus affecting 50 to 80 million worldwide, out of which $20-35$ million couples in Africa are expected to experience this problem. This can be extrapolated to 3 - 4 million Nigeria couples suffering from infertility (Thomas 1995). However an estimate of infertile couples in Ile-Ife has been put at $19 \%$ by Okonofua in 1995, although authors in previous studies in the other parts of Nigeria gave ranging estimates. In Africa, its prevalence is particularly high in sub-sahara African ranging from $20 \%$ to $60 \%$ (Ogunniyi, 1999). The objectives of the study were to; ascertain the rate of increase of female infertility in Osun State, the causes of infertility in Osun State, the age prevalence of female infertility and the type of infertility that is prevalent in Osun State.

\section{METHOD}

Case studies were carried out in four different medical centers to obtain information. These included, Obafemi Awolowo Teaching Hospital,
Ile-Ife (ISH), Obafemi Awolowo Teaching Hospital Ilesa, (WGH), Ladoke Akintola University Teaching Hospital Oshogbo (LAUTECH) and General Hospital Ikire (GHI). A total of 200 case notes were studied. Fifty case notes in each of the centers in the period 2001 2003. Data were generated using international classification of diseases and related health problems tenth revision (ICD-10)

Under the code number N97 to retrieve case notes of patients treated for infertility. Information extracted from the case notes were the age of the patients, type of infertility whether primary or secondary, causes and the treatment in the years under review. More so, the outcome of the treatment with regard to the number of patients that became pregnant after treatment was also evaluated. The biostatistics section of each medical center assisted in procuring vital information such as the total number of gynaecology in the centers from $2001-2003$ and the total number of cases of infertility in the year under review. Coding and indexing section also helped in facilitating the retrieval of the case notes.

\section{RESULTS AND DISCUSSION}

The incidence of high infertility in women was established in all the four hospital centers selected for the study. The age range was $15-55$ years with a mean of 35 years. The mean weight was $62 \mathrm{~kg}$ with a range of $40-74 \mathrm{~kg}$.

Table 1:

Causes and \% Prevalence of Infertility in Osun State

\begin{tabular}{|c|c|c|c|c|c|c|}
\hline \multirow{2}{*}{$\begin{array}{l}\text { \% frequency of } \\
\text { the causes of } \\
\text { infertility }\end{array}$} & \multirow[t]{2}{*}{$\%$ of age } & \multicolumn{5}{|c|}{ Prevalence of infertility } \\
\hline & & $\begin{array}{l}15-25 \text { years } \\
17.0)\end{array}$ & $\begin{array}{l}26-35 \text { years }( \\
(31.5)\end{array}$ & $\begin{array}{l}36-45 \text { years } \\
(50.5)\end{array}$ & $\begin{array}{l}46-55 \text { years } \\
(1.0)\end{array}$ & $\begin{array}{l}\text { Total } \\
(100.0)\end{array}$ \\
\hline Male factor & $13(6.5)$ & $2(15.4)$ & $4(30.8)$ & $7(54.0)$ & $0(0.0)$ & $13(100.2)$ \\
\hline Tubal factor & $79(39.5)$ & $13(16.5)$ & $25(31.6)$ & $40(50.6)$ & $1(1.3)$ & $79(100.0)$ \\
\hline Uterine factor & $60(30.0)$ & $10(16.7)$ & 19(31.7) & $30(50.0)$ & $1(1.7)$ & $60(100.1)$ \\
\hline Cervical factor & $6(3.0)$ & $1(16.7)$ & $2(33.3)$ & $3(50.0)$ & $0(0.0)$ & $6(100.0)$ \\
\hline Ovarian factor & $26(13.0)$ & $5(19.2)$ & $8(30.8)$ & $13(50.0)$ & $0(0.0)$ & $26(100.0)$ \\
\hline PID & $11(5.5)$ & $1(9.1)$ & $4(36.4)$ & $6(54.5)$ & $0(0.0)$ & $11(100.0)$ \\
\hline Endometriosis & $5(2.5)$ & $0(0.0)$ & $2(40.0)$ & $3(60.0)$ & $0(0.0)$ & $5(100.0)$ \\
\hline Coital & $0(0.0)$ & $0(0.0)$ & $0(0.0)$ & $0(0.0)$ & $0(0.0)$ & $0(0.0)$ \\
\hline Total & & & & & & $200(100.0)$ \\
\hline
\end{tabular}


Table 1 shows the more common causes of infertility. About 39.5\%, 30\%, 13\% and 6.5\% cases of infertility reported were caused by tubal factor, uterine factor, ovarian factor and male factor respectively. Less common causes were pelvic infection disease, 5.5\%, cervical factor, $3.0 \%$ and endometriosis, $2.5 \%$. Of the 200 cases of infertility evaluated, coital difficulties had $0.0 \%$ cause of infertility in the age range. All the common causes of infertility excluding coital difficulties were most pronounced in the age range 36 - 45years. Precisely, 40 (50.6\%) tubal factor, $30(50.0 \%)$ uterine factor, $13(50.0 \%)$ ovarian factor, 7 (54.0\%) male factor, 6 (54.5\%) PID, 3 (50.0\%) cervical factor and 3(60.0\%) endometriosis were reported in the age range $36-$ 45years. Tubal factor $1(1.3 \%)$ and uterine factor $1(1.7 \%)$ were the only causes in the age range 46 $-55 y e a r s$.

Table 2:

Percentage of types of infertility in four centers

\begin{tabular}{l|lllll}
\hline $\begin{array}{l}\text { Types of } \\
\text { Infertility }\end{array}$ & ISH & WGH & LAUTECH & GHI & $\%$ \\
\hline Primary & 15 & 10 & 12 & 8 & 22.5 \\
Secondary & 35 & 40 & 38 & 42 & 77.5 \\
Total & 50 & 50 & 50 & 50 & 100 \\
\hline
\end{tabular}

The primary objective of this work was to evaluate the prevalence of infertility in women, the common cause as well as any probable vulnerable age range in women living in Osun State. The outcome of the study has shown that there is a high incidence of infertility in these women with $51.5 \%$ of all of gynaecological admission within the year 2001 - 2003 in the four centers being infertility. Obafemi Awolowo University Teaching Hospital, Ile-Ife had infertility as $59.4 \%$ of all gynaecological admission. This is an increase when compared to the research done by Okonofua in 1995, in which infertility accounted for only
$19 \%$ of all gynaecological admission in Ile-Ife. Worthy of note is the fact that all the common causes of infertility excluding coital difficulties were most pronounced in women within the age range of 36 - 45years (50.5\%). 22\% of infertility occurred between ages 15 - 25years, 26.5\% between 26 - 35years and 1\% between 46 55 years in the females under the year reviewed.

The lower limit of 15years was taken because in this environment average female puberty year is $13 y e a r s$ and most pregnancy starts around 15years (Ogunniyi, 1999). The upper limit is 46 - 55years because menopause sets averagely in this environment at 46 years.

\section{REFERENCES}

Belsey, M.A. (1976):. The Epidemiology of Infertility: a Review with Particular Reference to sub-Saharan Africa. Bulletin of the World Health Organization 54:319-341.

Ogunniyi, S.O, Makinde, O.O and Dare, F.O (1999): Abortion Related Deaths in Ile-Ife, Nigeria. African Journal of Medicine and Medical Science 19(4): 271 - 274.

Okonofua, F.E (1996): Case against new reproductive technologies in developing countries. British Journal Of Obstetrics and Gynaecology. 103:957 - 962.

Thomas K.D, Adeoye and Olusanya, O.O. (1995): Biochemical Markers in Seminal Plasma of Sub-Fertile Nigeria Men. Tropical Journal of Obstetric and Gynaecology. 15:19.

W.H.O (1991). Infertility: A tabulation of available data on prevalence of primary and secondary infertility. Programme on Maternal and Child Health and Family Planning, Division of Family Health. World Health Organization: Geneva. 